International Journal of Engineering \& Technology, $7(2.6)(2018) 98-101$
International Journal of Engineering \& Technology
SPC
Website: www.sciencepubco.com/index.php/IJET
Research Paper

\title{
Mobile in learning: Enhancement of information and communication technologies
}

\author{
Jossy P George ${ }^{1}$, Vinay M ${ }^{2 *}$ \\ ${ }^{1}$ Christ Institute of Management, Lavasa, Pune, Maharashtra, India \\ ${ }^{2}$ Christ University, Bangalore, Karnataka, India \\ *Corresponding author E-mail: vinay.m@christuniversity.in
}

\begin{abstract}
The technological advancement in the world has changed the people's life. The people view point towards the usage of technologies in different fields like business, tourism, communication, education etc. has changed. Mobile learning can give flexible learning environment for the user. It can also increase the participant number in the online teaching learning process. This paper discusses about the effectiveness of the current technologies used in higher education system. It profiles the advantages of using mobile in accessing the university central system for teaching and learning. It also discusses about mobile digital book with augmentation, which can be used to improve the teaching and learning process of the different departments in the university
\end{abstract}

Keywords: Information and Communication Technology (ICT), Mobile Learning, Learning Management System, Education Technology

\section{Introduction}

The world has seen various technological changes in the past several decades. One among the most influenced change in the world is the increased usage of mobile devices. Now mobile devices are one of the inevitable part of people's day to day life. In the present digital world most people use a smart phone for the socialization, knowledge discovery, communication, scheduling, organizing, remainder and notification, webinar, online conference, etc. The encouragement to use the mobile devices in the education system can do the betterment of the existing pedagogy.

At present the advancement of education system in most of the universities are most important part of the growth of the countries. Many education institutions are trying to implement a central system with a common platform for the teaching and learning process. The government in all the countries are giving more focus on the enhancement of ICT usage through web portals, Learning Management System (LMS), Course Management System (CMS), Content Management System, mobile learning, social learning, learning through game, cultural exchange and internationalization [1]. The sudden boom in the usage of mobile device is shown an effective way to reach the education into the figure tips of people. One of the effective method of changing the pedagogy is the usage of mobile devices in teaching learning process.

This paper discus about the usage of mobile device in the Indian higher education university. The mobile devices give a flexibility for both teachers and students in accessing the university central system for the teaching and learning process. The university central system discussed in this paper has various parts like digital curriculum, teaching-learning platforms, various applications and tools for teaching-learning process. It provides e-assessment and learning data analytics. It also has an educational database which helps to store the teachers and student's data.
The remaining paper is classified into different sections. Section II give brief insight on the few of previous research works on mobile learning. Section III gives a brief on the effectiveness of existing technologies used in teaching learning process. The proposed system is briefed in the section IV.Section V give a description on various application used in the teaching-learning process in different subjects in the university. The usage effectiveness is discussed in section VI and the paper is concluded in the section VII.

\section{Related Work}

This section of the paper gives a brief on few of the previous research work on mobile learning from 2006 to 2016.

Duc Phuong Nguyen, Martin Guggisberg, and Helmar Burkhart [2] discussed about a mobile learning framework CoMobile. They also discussed on the applications that can used in mobile learning platform to improve its effectiveness. The authors suggest the use of speech recognition, character recognition and text to speech application usage in the mobile learning platform. The frame work discussed in the paper is an open source platform. It also helps to do collaborative work in mobile platform. Yuan-Chen Liu, et al., [3] has performed a research work on mobile activity design. The performed a study to evaluate the digital learning activities of students on a conceptual learning environment. They also studied student's attitude and learning behavior towards he digital learning environment. N.Cavus and H. Uzunboylu [4] discussed about a mobile application which can used for the environmental studies in their research work. The authors developed a web-based platform for the environmental education. GuoLong, JinYun WANG and ZhongMing LI [5] discussed about the mobile learning in their research work. The profiled the cognitive learning, context-based learning, action, experimental and informal learning using mobile learning platform in their research work. 
Shuyun Han [6] discussed on the situated learning using mobile learning platform. They also discussed about a design for the modularity learning using mobile learning platform. Travis Kowalski [7] discussed about a mobile portal application for the teaching and learning process. The authors proposed a model in their research work which can be used by the teachers and students to access mobile based learning resources in the classroom environment. Hana Sadat Fahim Hashemmi, Fatemeh Orooji and FattanehTeghiyareh[8] profiled a mobile based context aware learning management system in their research work. The authors discussed about the analysis of students learning behaviour using the application. They also confirm that the application showed better teaching-learning outcome compare to the existing method.

Song Wei [9] discussed about an android based mobile learning platform design and implementation in their research work. According to the author the mobile learning applications can give better learning experience and improve student's performance. H.Kopackova and R. Bilkova [10] as performed a survey study on the impact of mobile based learning in their research work. The major goal of this research work was to understand the student's acceptance rate on the usage of mobile based learning environment. Wan Abdul Rahim Won Mohd Isa, et al., [11] performed a study on the factors which involved in the mobile learning evolving in the self-learning environment. The study was performed using a survey. They also studied the effectiveness of mobile learning environment. AnshariMet al.,[12] discussed about a mobile learning platform based on the cloud computing. The authors discuss about the quality and effectiveness of cloud based mobile learning. The authors profiled a framework which improve the mobile based learning quality compare to existing applications.

\section{Effectiveness of the existing technologies used}

A survey study is conducted among students and teachers to understand the existing technological usage and its effectiveness in teaching and learning process. The survey was conducted among 200 teachers and 500 students. The total response received is $80 \%$ and maximum response was from students.

In the survey the first evaluation was on ICT awareness among teachers and students. Fig 1 shows the ICT awareness response from teachers and fig 2. shows the students response. The survey also evaluated the effectiveness of existing technologies in teaching and learning process.

From the result shown in fig 1 . it is evident that the $100 \%$ teachers are aware of ICT in education. 90 responses confirm the presence of ICT facilities in their institutions. 145 teachers are aware of how to use ICT in teaching. 95 of them confirm the presence of ICT training for teachers in their institution. 122 of the response confirm the usage of ICT technologies in their daily teaching. The preference of ICT usage in teaching was shown by 138 responses. 145 responses confirm that they save time by using ICT in teaching process.

Majority of the response from teachers conforms that teachers does not share their course materials with other faculties from different institutions. Only 16 teachers confirm the presence of any kind of Moodle facility in their institution.

Figure 2 shows the ICT awareness response from the students. From the result it is evident that the $100 \%$ respondent are aware of ICT in education. 320 responses confirm the presence of ICT facilities in their institutions. 245 students are aware of how to use ICT in learning.

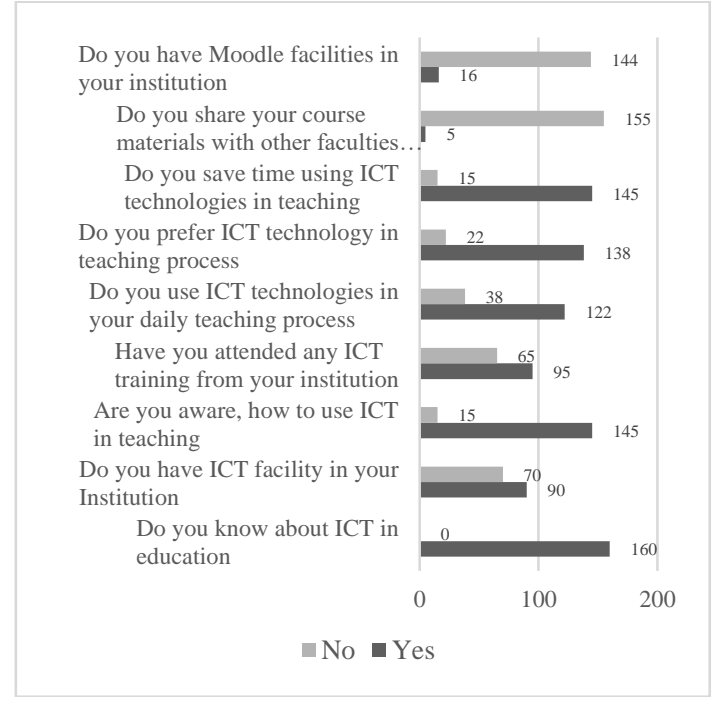

Fig. 1: Example of an image with acceptable resolution

The student's response confirms the absence of ICT training for students in their institution. 368 of the response confirm the usage of ICT technologies in their daily leaning process.

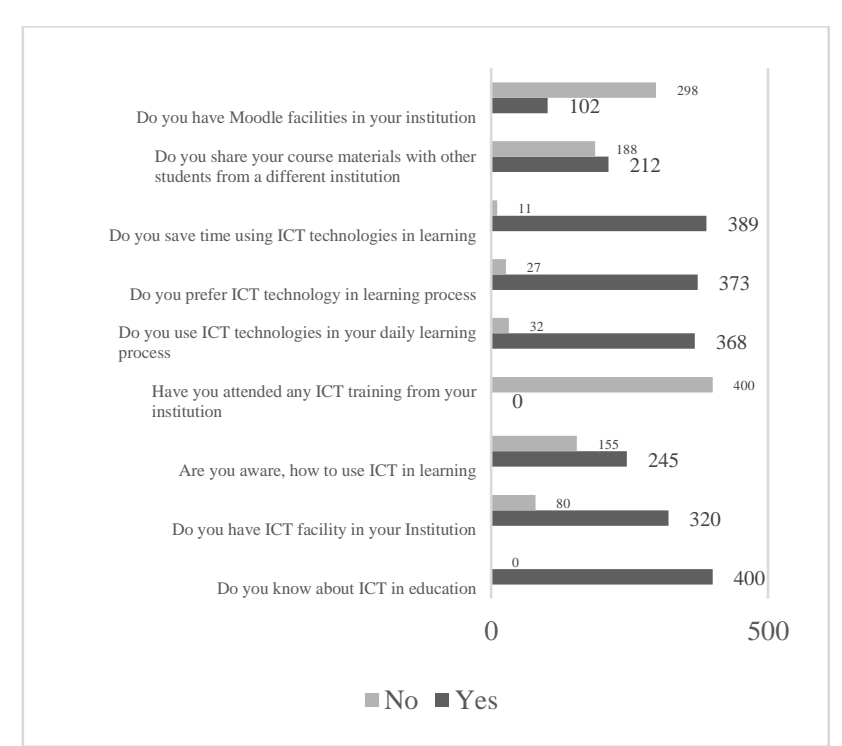

Fig. 2: ICT awareness among students

The preference of ICT usage in learning was shown by 373 responses. 389 responses confirm that they save time by using ICT in learning process. 212 of response conform the students share their course materials with other students from different institutions. Only 102 responses confirm the presence of any kind of Moodle facility in their institution.

In the survey majority of the teachers confirm that the usage of ICT in teaching learning is completely effective (45\%). $23 \%$ the teachers responded as very effective.

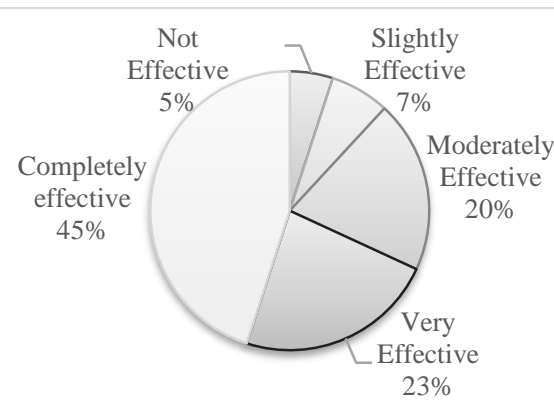

Fig. 3: Survey Response of Teachers on ICT Effectiveness 
$20 \%$ of them responded as moderately effective. $7 \%$ is confirmed as slightly effective and 5\% responded as not effective. The response is shown in the figure 3. Majority of the students confirm that the usage of ICT in teaching learning is completely effective (46\%). $24 \%$ the students responded as very effective. $22 \%$ of them responded as moderately effective. $8 \%$ is confirmed as slightly effective and $0 \%$ responded as not effective. The response is shown in the figure 4.

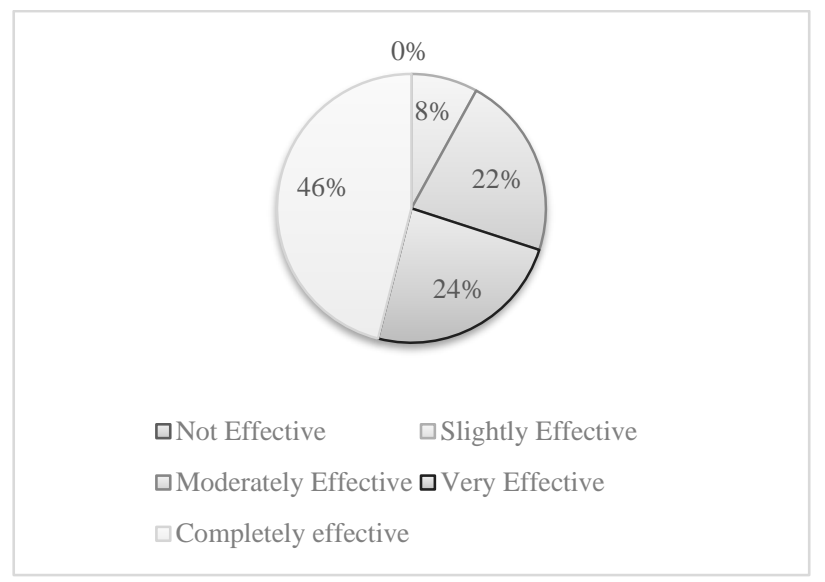

Fig. 4: Survey Response of students on ICT Effectiveness

\section{Proposed system}

The university learning management system (ULMS) has different parts such as digital curriculum, teaching learning platform, applications and tools, e- assessment, learning data analytics and educational database. The proposed system in this paper is a mobile application which can be used to access the ULMS. Figure 5. shows the mobile based application architecture. The mobile application has three modules such as authentication module, teacher module and student module.

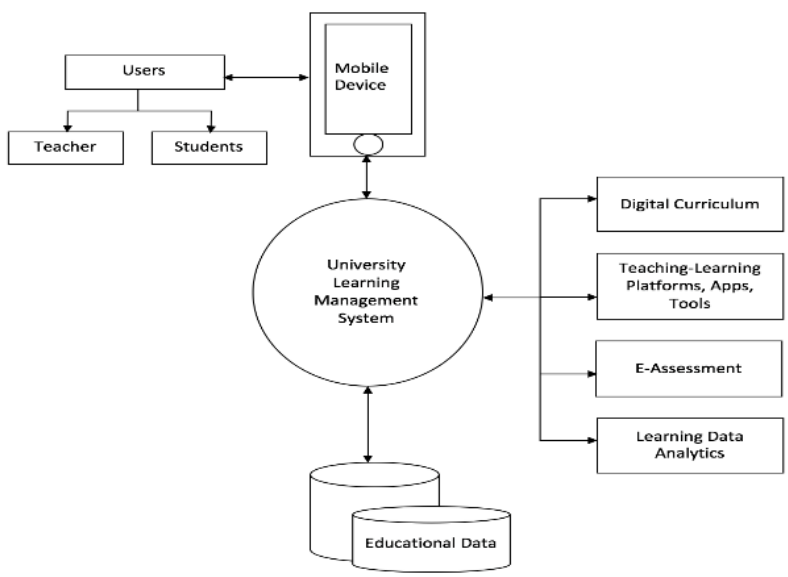

Fig. 5:Proposed system to access the University Learning Management System using mobile device

The authentication module allows the user to login to the application using their user name and password. Then the next module is teacher module. The various activities of the teacher's module are designing the lesson and resources to be used, scheduling and adding the students to the activities. The teacher module also allows the teacher to set the questions in e-assessment and access the students' performance and learning pattern using learning data analytics to identify the weak learner.

The student module in the application allow the students to access the lesson and resources provided by the teachers. They can access various learning application and tools given by the teachers. They can also access other application for the learning process. This module allows the student to access the e-assessment to attempt the test. The student can also access the learning data analytics to see their performance.

\section{Mobile digital book with augmentation ap- plication}

The proposed application is a digital book with augmentation. In the proposed application the camera of the mobile device is used to track the code in the book. The code is used as an index in the server.

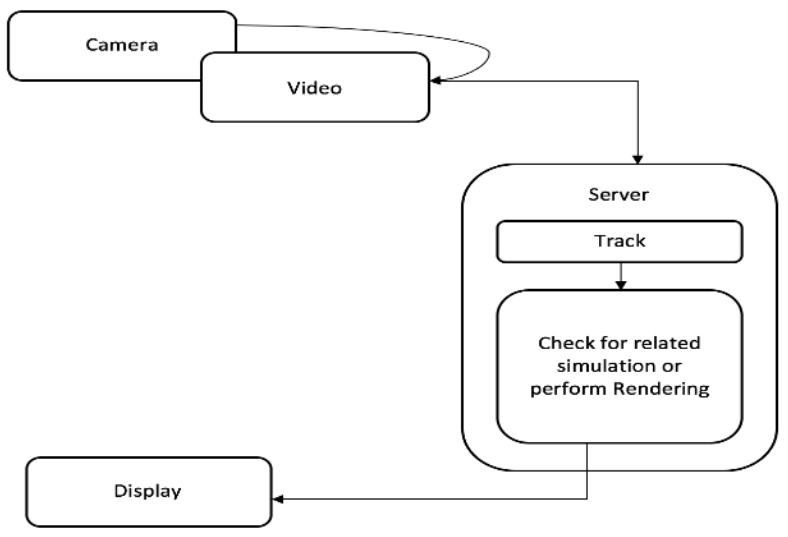

Fig. 6: Architecture of the Proposed Mobile Digital Book with Augmentation

The server stores a simulation, or it perform a rendering of the image to provide an augmented display of the data received using the camera.

\section{Effective Analysis ULMS using Mobile De- vice}

The effectiveness of the application is evaluated using a survey among student population. The survey was conducted on 280 students from different course work. From figure 3 it is evident that the applications showed high level of effectiveness in teaching and learning process. $57 \%$ of the survey response conformed the complete effectiveness. $34 \%$ confirm the applications as very effective and $9 \%$ conforms the application as moderately effective.

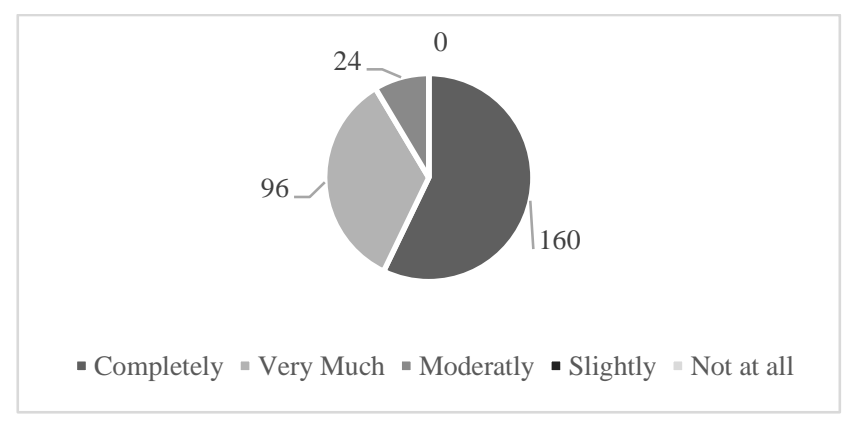

Fig 7: Effectiveness of using ULMS and teaching learning application in Mobile device.

\section{Conclusion}

Current digital world is full of tech savvy population. People are using technologies in every activity they perform in their day to day life. Mobile has become the major part of their digital life. It also influenced the education system. Teachers and learners are using their mobile devices for browsing new knowledge, learning 
concept, sharing the knowledge, etc. This paper discussed the effectiveness of the existing technologies in education system and proposed a mobile devices-based architecture for the teaching learning process. It also profiled a mobile digital book with augmentation.

\section{References}

[1] Abazi-Bexheti, L., Apostolova-Trpkovska, M. and Kadriu, A., 2014, May. Learning management systems: Trends and alternatives. In Information and Communication Technology, Electronics and Microelectronics (MIPRO), 2014 37th International Convention on (pp. 773-777). IEEE.

[2] Nguyen, D.P., Guggisberg, M. and Burkhart, H., 2006, December. Multimedia Information and Mobile-Learning. In Multimedia, 2006 ISM'06. Eighth IEEE International Symposium on (pp. 938-946). IEEE.

[3] Liu, Y.C., Tang, K.T., Huang, T.H., Wang, T.Y. and Istanda, V., 2007, October. Mobile learning activities design based on conceptual learning. In Frontiers In Education Conference-Global Engineering: Knowledge Without Borders, Opportunities Without Passports, 2007. FIE'07. 37th Annual (pp. F4J-1). IEEE.

[4] Cavus, N. and Uzunboylu, H., 2008, December. A collaborative mobile learning environmental education system for students. In Computational Intelligence for Modelling Control \& Automation, 2008 International Conference on (pp. 1041-1046). IEEE..

[5] Ruan, G., Wang, J. and Li, Z., 2009, December. Theoretical foundations of mobile learning mediated by technology. In Information Science and Engineering (ICISE), 2009 1st International Conference on (pp. 5435-5438). IEEE.

[6] Han, S., Kong, W., Liu, Q. and Zhou, L., 2010, October. Design and implementation of mobile English learning. In Intelligent System Design and Engineering Application (ISDEA), 2010 International Conference on (Vol. 1, pp. 510-513). IEEE.

[7] Kowalski, T., Israel, K., Sreedharan, A. and Zong, Z., 2011, October. Mobile learning experience in the calculus classroom In Frontiers in Education Conference (FIE), 2011 (pp. F1J-1). IEEE.

[8] Hashemi, H.S.F., Orooji, F. and Taghiyareh, F., 2012, November A context-aware mobile learning model for web-based learning environments. In Telecommunications (IST), 2012 Sixth International Symposium on (pp. 924-928). IEEE.

[9] Wei, S., 2013, December. The Design and Implementation of a Mobile Learning Platform Based on Android. In Information Science and Cloud Computing Companion (ISCC-C), 2013 International Conference on (pp. 345-350). IEEE.

[10] Kopackova, H. and Bilkova, R., 2014, December. Mobile devices in learning-Are students ready for the change?. In Emerging eLearning Technologies and Applications (ICETA), 2014 IEEE 12th International Conference on (pp. 39-44). IEEE.

[11] Isa, W.A.R.W.M., Lokman, A.M., Mustapa, M.N., Sah, I.N.M., Hamdan, A.R. and Luaran, J.E., 2015, December. Exploring the adoption of blended learning: Case of mobile learning. In Artificial Intelligence, Modelling and Simulation (AIMS), 2015 3rd International Conference on (pp. 359-364). IEEE.

[12] Anshari M, Almunawar MN, Shahrill M, Wicaksono DK, Huda M Smartphones usage in the classrooms: Learning aid or interference? Education and Information Technologies. 2017 Nov 1;22(6):306379. 